\title{
Pengaruh Parameter Fisika dan Mikrobiologi Leachet terhadap Kesehatan Lingkungan di TPA Muara Fajar Rumbai Pekanbaru
} The Influence of Physical Parameters and Microbiology Leachet to the
Health of Environment at TPA muara Fajar Rumbai Pekanbaru

\author{
Riski Novera Yenita, Ade Pulasta Siprana
}

Staff Pengajar Stikes Al-Insyirah Pekanbaru

\begin{abstract}
ABSTRAK
Secara umum kondisi sampah kota memperlihatkan karakteristik yang khas. Kondisi sampah kota memiliki komposisi terbesar sampah organik dengan nilai rata-rata 79,164\%, sedangkan sampah anorganik hanya sebesar 20,836\%. Jenis penelitian ini adalah metode survey, dimana TPA Muara Fajar Pekanbaru dijadikan lokasi pengambilan sampel. Sampel yang diambil kemudian dianalisis kadar fisika dan biologi leachet di laboratorium, selanjutnya data yang didapat dilakukan analisis secara deskriptif sesuai dengan SNI 06-2412-1991. Sumber data penelitian yaitu wawancara, observasi dan pemeriksaan laboratorium. Dua kode sampel pada air lindi didapatkan hasil analisis bahwa pada kode sampel I dan II suhu yang didapatkan adalah $25^{\circ} \mathrm{C}$. TSS pada kode sampel I didapatkan hasil sebesar $70 \mathrm{mg} / \mathrm{l}$ dan kode sampel II $190 \mathrm{mg} / \mathrm{l}$. pH pada kode sampel I dan II didapatkan hasil sebesar 8, sedangkan untuk kadar E.Coli pada kode sampel I dan II didapatkan hasil tidak terhingga.
\end{abstract}

Kata kunci : kadar fisika dan biologi, leachet dan kesehatan lingkungan

\section{ABSTRACT}

The general condition of "City trash" shows typical characteristics. The The city waste largest had a composition of the organic worth rata-rata $79,164 \%$, the inorganic waste was only 20,836\%. Type of research was a survey method. Location sampling was in Muara Fajar landfill Pekanbaru. Samples were taken and analyzed the level of physics and biology leachet in the laboratory, data obtain were then analyzed using descriptive, in accordance with SNI 06-2412-1991. The data research the interview, observation and laboratory. Two code samples to water lindi obtained analysis on codes sample that I and II or temperature is $25^{\circ} \mathrm{C}$. TSS on codes I got the sample of $70 \mathrm{mg} / \mathrm{l}$ and sample code II $190 \mathrm{mg} / \mathrm{l}$. ph on codes samples I and II obtained a result of 8 , as for the sample e.coli on codes I and II obtained the infinite.

Kata kunci : level of physics and biology, leachet and environmental health

\section{PENDAHULUAN}

Sejalan dengan meningkatnya laju pembangunan di semua sektor pada kondisi saat ini dan tahun - tahun yang akan datang di daerah perkotaan, telah memicu terjadinya peningkatan laju urbanisasi. Konsekuensi logis dari semua itu adalah meningkatnya aktivitas perkotaan di berbagai sektor, baik sektor perumahan, industri, perdagangan maupun sektor lainnya. Salah satu dampak dari aktivitas tersebut adalah limbah padat atau sampah. Sampah adalah limbah yang bersifat padat terdiri dari bahan organik maupun anorganik dari sisa atau residu yang timbul akibat aktifitas manusia yang dianggap tidak berguna lagi dan harus dikelola agar tidak membahayakan lingkungan dan melindungi investasi pembangunan. Secara umum kondisi sampah kota memperlihatkan karakteristik yang khas. Kondisi sampah kota memiliki komposisi terbesar sampah organik dengan nilai rata-rata $79,164 \%$, sedangkan sampah anorganik hanya sebesar 20,836 \% dengan besaran simpangan baku sebesar 9,5\% (Sudarwin, 2008).

Sejumlah 384 kota yang menimbulkan sampah sebesar $80.235,87$ ton setiap hari, penanganan sampah yang diangkut untuk dibuang ke Tempat Pembuangan Akhir (TPA) adalah sebesar 4,2\%, yang dibuang ke sungai $4,9 \%$, yang dibakar $37,6 \%$ dan tidak tertangani sebesar $53,3 \%$. Di wilayah perkotaan volume sampah diperkirakan akan meningkat $3-5$ kali lipat dalam 20 tahun ke depan, dengan asumsi laju pertambahan penduduk di wilayah perkotaan sama seperti saat ini dan terjadi peningkatan limbah yang dihasilkan per kapita. (Sudarwin, 2008) .

${ }^{1}$ Alamat Korespodensi: Riski Novera Yenita, Email: qynas85@gmail.com 
Kehadiran tempat pemrosesan akhir (TPA) seringkali menimbulkan dilema. TPA dibutuhkan, tetapi sekaligus tidak diinginkan kehadirannya di ruang pandang. Kegiatan TPA juga menimbulkan dampak gangguan antara lain: kebisingan, ceceran sampah, debu, bau, dan binatang-binatang vektor. Belum terhitung ancaman bahaya yang tidak kasat mata, seperti kemungkinan ledakan gas akibat proses pengolahan yang tidak memadai. Lebih lanjut, sampah juga berpotensi menimbulkan konflik sosial dengan masyarakat yang ada di sekitarnya akibat penguasaan lahan oleh kelompok orang yang hidup dari pemulungan. Konflik bisa memuncak pada protes dari masyarakat kepada pengelola TPA untuk menutupnya dan memindahkannya ke tempat yang lain. (Soedrajat, 2010)

Permasalahan sampah pada tahun-tahun terahir ini semakin kompleks seiring dengan bertambahnya jumlah penduduk dan pertumbuhan industri. Sampah perkotaan merupakan salah satu persoalan yang rumit yang dihadapi oleh pengelola kota dalam menyediakan sarana dan prasarana perkotaannya. Tempat Pemprosesan Akhir (TPA) sampah dengan sistem Lahan Urug Saniter (LUS) merupakan alternatif penanganan akhir sampah kota. Namun dengan menyingkirkan sampah kota ke TPA bukan berarti masalahnya sudah selesai, sebab TPA itu sendiri bila tidak dikelola dengan baik akan menimbulkan masalah baru (Darsono, 2008).

Hingga saat ini pengelolaan persampahan oleh pemerintah masih menitik beratkan pada pengelolaan ketika sampah telah dihasilkan. Kegiatan pengumpulan, pengangkutan, dan pembuangan sampah ke Tempat Pemprosesan Akhir (TPA) sampah menjadi hal yang menonjol dilakukan oleh pemerintah. Meskipun dalam bentuk pengelolaan sampah berupa pengurangan sampah sejak dari sumbernya, pemanfaatan atau penggunaan kembali, daur ulang dan pengomposan sampah secara maksimal (Dwi, 2010).

Sampah mempunyai potensi untuk menimbulkan pencemaran dan menimbulkan masalah bagi kesehatan. Pencemaran dapat terjadi di udara sebagai akibat dekomposisi sampah, dapat pula mencemari air dan tanah yang disebabkan oleh adanya rembesan (leachate). Tumpukan sampah dapat menimbulkan kondisi lingkungan fisik dan kimia menjadi tidak sesuai dengan kondisi normal. Hal ini dapat menyebabkan kenaikan suhu dan perubahan $\mathrm{pH}$ tanah maupun air yang menjadi terlalu asam atau basa. Tumpukan sampah dapat menjadi sarang atau tempat berkembang biak bagi berbagai vektor penyakit, misalnya : lalat, tikus, nyamuk, dan lain sebagainya, sehingga dapat menimbulkan penyakit. (Suhartini, 2008)

Sesungguhnya, sumber masalah yang lebih besar adalah lindi (leachet), sehubungan dengan pengolahan yang tidak memadai, yang bila masuk ke badan air yang dikonsumsi oleh masyarakat bisa menimbulkan penyakit parah dan kematian. Bahaya lindi inilah yang perlu dicegah agar tidak sampai menimbulkan gangguan kesehatan yang bermacam-macam. Hasil kajian menemukan masih berisikonya pemanfaatan TPA bagi kesehatan manusia dengan metoda pengurugan berlapis terkendali (controlled landfill). (Soedrajat, 2010)

Pencemaran yang timbul disebabkan oleh adanya timbunan limbah cair lindi. Lindi yang tidak dikelola dengan baik akan mencemari diantaranya akifer dan sumber air minum, karena cairan ini memiliki kandungan zat organik dan zat anorganik yang tinggi. Pencemaran air oleh lindi merupakan salah satu masalah yang paling serius dalam aplikasi Lahan Urug Saniter dimana sampah diurug ke dalam tanah khususnya pada daerah yang mempunyai curah hujan tinggi. Oleh karena itu perlu dibuat suatu pengolahan lindi pada TPA supaya tidak terjadi pencemaran tanah, air permukaan dan air tanah.

Air lindi mengandung bahan-bahan kimia baik organik maupun anorganik dan sejumlah bakteri baik bersifat patogen ataupun tidak patogen. Komponen yang terkandung didalamnya antara lain komponen organik terlarut, komponen anorganik, logam berat dan komponen organik xenobiotic yang biasanya didapatkan dalam konsentrasi rendah namun diduga menimbulkan efek toksik. Adanya air lindi baik yang ditampung di kolam penampungan untuk selanjutnya dialirkan ke sungai setelah melalui beberapa kolam atau yang langsung meresap ke talam tanah jelas akan mempengaruhi keberadaan air sumur penduduk atau kualitas air sumur yang ada di sekitarnya. Air sumur penduduk di sekitar TPA merupakan sumber air utama bagi masyarakat dan para pemulung, karena untuk seluruh kebutuhan air semua dipenuhi dari air sumur baik untuk memasak, MCK, memberi makan ternak dan kebutuhan yang lain. Adanya perubahan kualitas air karena pengaruh air lindi dari TPA jelas akan mempengaruhi pengguna air sumur khususnya bagi kesehatannya. Oleh karena itu penting untuk mengkaji keberadaan TPA khususnya karakteristik fisika dan kimia air lindi tersebut. (Suhartini, 2008)

Di kota Pekanbaru terdapat satu Tempat Pemrosesan Akhir (TPA) yaitu di muara fajar Kecamatan Rumbai. Pengolahan sampah di TPA ini hanya dengan teknik open dumping tanpa ada pengolahan lebih lanjut. Air lindi yang dihasilkan oleh timbunan sampah tidak diolah lebih lanjut. Pencemaran air lindi diperkirakan telah mencemari air dan tanah disekitar TPA. Setelah dilakukan survei di lapangan, sanitasi lingkungan TPA tidak saniter (tidak sehat) seperti sarana pembuangan sampah tidak ada, sampah ditumpukan di lokasi TPA Muara Fajar, sarana penyediaan air bersih masih mengunakan sumur control TPA Muara Fajar, sedangkan sarana pembuangan air limbah di sekitar tidak ada, air limbah 
dibiarkan merembes begitu saja disekitar lingkungannya sedangkan sarana untuk pembuangan kotoran manusia masih sederhana. Luas TPA Muara Fajar lebih kurang sembilan hektar, dan didirikan pada tahun 1982, sementara sistem pengelolaan sampah di TPA Muara Fajar dilaksanakan dengan dua cara yaitu dengan cara Dumping, yaitu sampah dibuang atau diletakkan begitu saja di tanah lapang, jurang untuk sampah anorganik, sedangkan sampah organik dikelola dengan cara memanfaatkan sampah dijadikan compos (composting) atau pupuk dengan proses dikomposisi zat organik oleh kuman-kuman pembusuk pada kondisi tertentu (Dinkes, 2009).

\section{METODE}

Tempat pengambilan sampel yaitu di TPA Muara Fajar Pekanbaru. Tempat untuk melakukan pemeriksaan sampel analisis leachet di Laboratorium Ekologi Perairan Fakultas Perikanan Universitas Riau Pekanbaru. Waktu penelitian dilaksanakan pada bulan Januari-Juni Tahun 2014. Metode yang digunakan dalam penelitian ini adalah survei, dimana TPA Muara Fajar Pekanbaru dijadikan lokasi pengambilan sampel. Sampel yang diambil kemudian dianalisis kadar fisika dan biologi leachet di laboratorium, selanjutnya data yang didapat dilakukan analisis secara deskriptif sesuai dengan SNI 06-2412-1991.

Data yang diperoleh dari pemeriksaan di laboratorium diolah secara manual dalam bentuk tabel dan hasil yang diperoleh tersebut akan dibandingkan dengan keadaan yang seharusnya menurut persyaratan yang telah ditentukan. Analisis data berupa analisa univariate, dimana data disajikan dalam bentuk distribusi frekuensi.

\section{HASIL}

Hasil analisis laboratorium kualitas air lindi TPA Muara Fajar Rumbai Pekanbaru disajikan dalam tabel 1.

\section{Tabel 1}

Hasil Analisis Kualitas Lindi TPA Muara Fajar Kota Pekanbaru

\begin{tabular}{lccc}
\hline \multirow{2}{*}{ Parameter } & Satuan & \multicolumn{2}{c}{ Kode Sampel } \\
\cline { 3 - 4 } & & I & II \\
\hline Suhu & ${ }^{\circ} \mathrm{C}$ & 25 & 25 \\
TSS & $\mathrm{mg} / 1$ & 70 & 190 \\
pH & & 8 & 8 \\
E.Coli & $\mathrm{Jlh} / 100 \mathrm{ml}$ & $\sim$ & $\sim$ \\
\hline
\end{tabular}

Sistem Pengelolaan sampah di TPA Muara Fajar dilaksanakan dengan dua cara antara lain dengan cara Dumping, sampah dibuang atau diletakkan begitu saja di tanah lapang dan jurang untuk sampah anorganik, sedangkan sampah organik dikelola dengan cara memanfaatkan sampah untuk dijadikan kompos (composting) atau pupuk dengan proses dikomposisi zat organik oleh kuman-kuman pembusuk pada kondisi tertentu. Di TPA Muara Fajar memiliki 4 kolam pengolahan air lindi secara sederhana dan 4 bak kontrol. TPA Muara Fajar tidak memiliki Instalasi Pengolahan Air Limbah (IPAL) yang modern dan canggih.

\section{PEMBAHASAN}

\section{Parameter Fisika Air Lindi TPA Muara Fajar Kota Pekanbaru}

Suhu

Berdasarkan tabel di atas dapat dilihat bahwa kadar suhu untuk kode sampel I dan II berkisar $25^{\circ} \mathrm{C}$. Berdasarkan penjelasan diatas terlihat bahwa suhu untuk ini tidak sesuai dan tidak memenuhi persyaratan yang di tetapkan oleh Peraturan Menteri Kesehatan No.492 Tahun 2010 tentang persyaratan kualitas air minum.

Penelitian ini dilakukan pada 4 kolam (stasiun) pengolahan air lindi diperoleh keterangan bahwa Pada tiap stasiun terlihat penyebaran suhu yang hampir sama, sebaran suhu tertinggi pada setiap stasiun adalah pada pengamatan siang hari yaitu berkisar antara $30-$ $32^{\circ} \mathrm{C}$. Sedangkan sebaran suhu terendah terjadi pada pagi hari yang berkisar antara $23-26,5^{\circ} \mathrm{C}$. Ini menunjukkan bahwa pola fluktuasi suhu pada saluran perairan tersebut adalah rendah pada pagi hari, kemudian terjadi kenaikan suhu yang drastis pada siang hari, dan selanjutnya berangsur-angsur menurun pada sore sampai malam hari. Suhu dipengaruhi oleh faktor penyinaran sinar matahari dan proses dekomposisi yang terjadi pada tiap stasiun. Keterangan diatas bahwa tingginya suhu di air lindi TPA Muara Fajar Kota Pekanbaru dipengaruhi oleh faktor penyinaran sinar matahari dan proses dekomposisi yang terjadi di air lindi TPA Muara Fajar Rumbai Kota Pekanbaru.

\section{TSS}

Tabel 1 di atas dapat terlihat bahwa kadar TSS (Total Suspended Solid) pada kode sampel I berjumlah $70 \mathrm{mg} / 1$ dan kode sampel II berjumlah $190 \mathrm{mg} / 1$. Penjelasan diatas dapat dilihat bahwa kadar TSS untuk kode sampel I masih memenuhi persyaratan Keputusan Kementerian Lingkungan hidup No. 112 Tahun 2003 tentang baku mutu air limbah domestik sedangkan untuk kode sampel II sudah melebihi baku mutu yang ditetapkan oleh Keputusan Kementerian Lingkungan Hidup tentang baku mutu air limbah domestik yaitu berkisar $100 \mathrm{mg} / \mathrm{l}$.

Hasil penelitian yang dilakukan Ningsih (2013) menyebutkan bahwa kandungan TSS sebelum dan sesudah pengolahan yang tidak beda jauh antara sampel A1 $=0,2 \mathrm{mg} / 1, \mathrm{~A} 2=0,1 \mathrm{mg} / \mathrm{l}$ dan $\mathrm{A} 3=0,1$ $\mathrm{mg} / \mathrm{l}$ di pengaruhi oleh proses pemeriksaan sampel air lindi, yaitu pada saat pengeringan dalam oven yang 
kurang dari $1 \mathrm{jam}$, karena pengovenan bertujuan untuk menghilangkan kelembaban. Selanjutnya penelitian yang dilakukan oleh Priambodho (2005) yang dilakukan pada 4 kolam (stasiun) pengolahan air lindi diperoleh keterangan bahwa TSS tiap pengamatan menunjukan nilai yang beragam. Pada stasiun 1 terlihat, nilai TSS dari pengamatan pagi sampai sore hari mengalami kenaikan dari $14 \mathrm{mg} / \mathrm{l} \mathrm{sampai} 41 \mathrm{mg} / \mathrm{l}$, akan tetapi pada malam hari terjadi penurunan sampai $4 \mathrm{mg} / \mathrm{l}$. Hal ini diduga karena pada pagi sampai siang hari komposisi pasir dan lumpur akibat limpasan dari persawahan meningkat sedangkan pada malam hari komposisi pasir dan lumpurnya berkurang dapat dilihat dari penampakan air contoh yang lebih jernih daripada pagi, siang, dan sore. Pada stasiun 2 terlihat pola yang terus meningkat, pagi hari sebesar $23 \mathrm{mg} / \mathrm{l}$ sampai 27 $\mathrm{mg} / \mathrm{l}$ pada malam hari. Kondisi ini diduga karena adanya peningkatan kandungan pasir halus, lumpur, dan bahan organik tidak terlarut yang ikut terbawa air lindi. Lain halnya dengan stasiun 3 dan 4, pada pengamatan pagi sampai sore hari cenderung konstan, ke mudian mengalami kenaikan pada waktu malam hari sampai $76 \mathrm{mg} / 1$ (stasiun 3) dan $68 \mathrm{mg} / 1$ (stasiun 4). Nilai TSS yang lebih tinggi pada malam hari ini diduga karena sebelum pengamatan terjadi hujan sehingga sedimen dasar yang berupa lumpur dan pasir terangkat kepermukaan. Kadar TSS air lindi TPA Muara Fajar Rumbai Pekanbaru masih cukup tinggi sehingga perlu dilakukan pengolahan yang lebih lanjut sebelum dibuang ke lingkungan.

Hasil pengamatan yang dilakukan oleh peneliti didapatkan bahwa unit pengolahan air lindi yang ada di TPA Muara Fajar Kota Pekanbaru masih belum efisien, masih sangat sederhana (yaitu dengan menggunakan kolam-kolam penyaring dan tidak menggunakan instalasi pengolahan air limbah pengolahan air lindi) sehingga masih belum aman jika dibuang kelingkungan disekitar TPA Muara Fajar Kota Pekanbaru. Pemerintah Kota Pekanbaru harus segera dapat menyediakan instalasi pengolahan air limbah (air lindi) yang sesuai dengan standar lingkungan dalam melakukan pengolahan air lindi TPA Muara Fajar Kota Pekanbaru sehingga air lindi yang dibuang ke lingkungan aman buat biota air dan tumbuhan serta air bersih masyarakat yang tinggal di sekitar TPA Muara Fajar Kota Pekanbaru layak untuk dikonsumsi dan tidak mencemari sumber air bersih masyarakat.

\section{pH}

Berdasarkan tabel 1 dapat dilihat bahwa $\mathrm{pH}$ air lindi TPA Muara Fajar Kota Pekanbaru untuk kode sampel I dan II berkisar 8 dan sudah memenuhi persyaratan Keputusan Kementerian Lingkungan hidup No. 112 Tahun 2003 tentang baku mutu air limbah domestik yaitu berkisar antara 6-9. Hal ini sesuai dengan Keputusan Menteri Kesehatan No.492 tentang persyaratan kualitas air minum menyebutkan bahwa
$\mathrm{pH}$ kadar maksimum yang diperbolehkan berkisar antara 6,5-8,5.

Hasil penelitian yang dilakukan Indah et.al (2006)

di TPA sampah Batu Putih Kabupaten OKU menyebutkan bahwa nilai keasaman yang tinggi (nilai $\mathrm{pH}$ terendah) terlihat pada sumur pantau dan sumur penduduk yang berdekatan dengan TPA (dengan jarak $10 \mathrm{~m}$ dan $100 \mathrm{~m}$ ). Tingginya keasaman kedua sumur tersebut disebabkan karena terurainya bahan-bahan organik yang berasal dari lindi TPA yang masuk ke sumur penduduk.

Peneliti dapat menyimpulkan bahwa kadar $\mathrm{pH}$ air lindi di TPA Muara Fajar Kota Pekanbaru masih memenuhi persyaratan yang ditetapkan oleh Kementerian Lingkungan Hidup dan Kementerian Kesehatan. Tetapi harus melalui proses pengolahan yang lebih baik lagi sehingga air lindi yang dibuang ke lingkungan aman bagi biota air, tumbuhan serta sumber air bersih masyarakat yang tinggal di sekitar TPA Muara Fajar Kota Pekanbaru.

\section{Parameter Mikrobiologi Air Lindi TPA Muara Fajar Kota Pekanbaru}

\section{E.Coli}

Data dari hasil pemeriksaan laboratorium diatas pada Tabel 1 terlihat bahwa kandungan mikrobiologis pada air lindi TPA Muara Fajar Kota Pekanbaru untuk kode sampel I dan II berjumlah tidak terhingga. Dari penjelasan diatas dapat dilihat bahwa kadar mikrobiologi (E.coli) untuk kode sampel I dan II tidak memenuhi persyaratan Keputusan Menteri Kesehatan No.492 Tahun 2010 tentang persyaratan kualitas air minum ditetapkan bahwa bakteri E.coli tidak boleh ada dalam air minum.

Hasil penelitian yang dilakukan Indah et.al (2006) menyebutkan bahwa jumlah bakteri E.coli pada semua sumur pengamatan adalah tinggi. Jumlah kadar E.Coli yang tidak terhingga di dalam air lindi TPA Muara Fajar Kota Pekanbaru akan memberikan dampak yang buruk terhadap lingkungan dan kesehatan masyarakat dalam hal ini kehidupan biotan air, tumbuhan, air bersih yang digunakan oleh masyarakat yang tinggal di sekitar TPA Muara Fajar Rumbai Pekanbaru. Sehingga perlu dilakukan proses pengolahan yang lebih baik lagi atau menggunakan instalasi pengolahan air limbah (air lindi) yang lebih modern.

\section{KESIMPULAN}

\section{Parameter fisika}

Suhu air lindi TPA sampah Muara Fajar Pekanbaru yang tinggi dan tidak sesuai dengan standar lingkungan. TSS air lindi TPA sampah Muara Fajar Pekanbaru pada kode sampel I berjumlah $70 \mathrm{mg} / \mathrm{l}$ masih di bawah baku mutu sedangkan untuk kode sampel II berjumlah $190 \mathrm{mg} / 1$ sudah melebihi baku 
mutu. pH air lindi TPA Muara Fajar Pekanbaru pada kode sampel I dan II adalah 8 masih memenuhi baku mutu air limbah.

\section{Parameter Mikrobiologi (biologi)}

Kandungan E.Coli air lindi TPA Muara Fajar Pekanbaru pada kode I dan II berjumlah tidak terhingga.

\section{SARAN}

Berdasarkan hasil penelitian yang telah dilakukan peneliti di TPA Muara Fajar Kelurahan Muara Fajar Kecamatan Rumbai Pesisir Kota Pekanbaru, maka peneliti mengajukan beberapa saran yaitu: 1) Diharapkan kepada Dinas Kebersihan Kota Pekanbaru agar dapat mengolah sampah di TPA Muara Fajar Pekanbaru dengan menggunakan teknologi canggih sedangkan untuk air lindi dinas Kebersihan Kota pekanbaru harus menyediakan Instalasi Pengolahan air limbah sampah yang dibuang ke lingkungan aman buat kehidupan biota air, tumbuhan dan air bersih yang dikonsumsi oleh masyarakat yang tinggal di sekitaran TPA Muara Fajar Pekanbaru. 2) Sebaiknya ada kerjasama lintas sektoral antara Dinas Kebersihan Kota Pekanbaru dengan instatasi lain untuk mengatasi permasalahan sampah dan air lindi sehingga tidak menimbulkan dampak buruk terhadap kesehatan masyarkat yang tinggal di sekitar TPA Muara Fajar Pekanbaru. 3) Perlu dilakukan penelitian lebih lanjut untuk mengetahui pengaruh kimia air lindi terhadap lingkungan di TPA Muara Fajar Pekanbaru.

\section{DAFTAR PUSTAKA}

Indah, 2006. Pengaruh Lindi Tempat Pembuangan Akhir (TPA) Sampah Batu Putih Kabupaten OKU Terhadap Kualitas Air di Sekitar TPA. Jurnal Pengelolaan Lingkungan dan Sum Daya Alam Volume 4, Nomor 2, Juni 2006.

Ningsih, 2013. Perbedaan Kualitas Air Lindi Sebelum dan Sesudah Pengolahan di Tempat Pembuangan Akhir (Studi Kasus TPA Sampah Botubilotahu Kec. Marisa Kab. Pohuwato). Tesis Jurusan Kesehatan Masyarakat Fakultas Ilmu-Ilmu Kesehatan dan Keolahragaan, Universitas Negeri Gorontalo.

DepKes RI, 2010.Peraturan Menteri Kesehatan NO 492/MENKES/PER/IV/2010 Persyaratan Kualitas Air Minum.

KemenLH RI, 2003. Keputusan Menteri Negara Lingkungan Hidup NO 112 Tahun 2003 Tentang Baku Mutu Air Limbah Domestik.

Priambodho, 2005. Kualitas Air Lindi Pada Tempat Pembuangan Akhir Sampah Galuga Kabupaten Bogor. Departemen Manajemen Sumber Daya Perairan, Fakultas Perikanan dan Ilmu Kelautan, Institut Pertanian Bogor.

Sudarwin, 2008. Dampak Pencemaran Lingkungan Cetakan Kedua. Andi Offset, Yogyakarta.

Suhartini, 2008. Memproses Sampah. Penebar Swadaya, Jakarta. 